\title{
[ARTIGO RETRATADO] CORREÇÃO DE TEXTOS E CONCEPÇÕES DE LÍNGUA E VARIAÇÃO: RELAÇÕES NEM SEMPRE APARENTES
}

O Conselho Editorial da revista Trabalhos em Linguística Aplicada deciciu, após análise, proceder à retirada formal do seguinte trabalho:

BEZERRA, M. A.; QUEIROZ, M. A.; TABOSA, M. Correção de textos e concepções de língua e variação: relações nem sempre aparentes. Trab. Ling. Aplic., Campinas, 43 (2): 307-321, Jul./Dez. 2004. Disponível em: http://www.scielo.br/pdf/tla/v43n2/a07v43n2.pdf uma vez que o mesmo foi publicado, no mesmo ano, em outro periódico.

São Paulo, 29 de abril de 2014/Belo Horizonte, 29 de abril de 2014. 
Trab. Ling. Aplic., Campinas, 43 (2): 307-321, Jul./Dez. 2004

\title{
CORREÇÃO DE TEXTOS E CONCEPÇÕES DE LÍNGUA E VARIAÇÃO: RELAÇÕES NEM SEMPRE APARENTES ${ }^{1}$
}

\author{
MARIAAUXILIADORA BEZERRA \\ ANNE KARINE DE QUEIROZ \\ MARIANA QUEIROGA TABOSA \\ (Universidade Federal de Campina Grande)
}

\begin{abstract}
This paper has two main aims to be achieved. The first relates to identifyin $c c \ldots$ s of language and linguistic variety subjacent to school texts correction led by teachers of mot $^{t^{\prime}} \mathrm{cr}$. ngu whereas the second one concerns the elicitation of the relation between those concepts and the co ectio val ation. For that, two compositions were corrected and evaluated by a group of teachers to b. As the grades given, it has been required a justification. The analysis was based on theoretical princir' is ' $\eta$ relatio, to teacher training, correction/ evaluation and language concepts as well. The results point that ${ }^{\dagger}$ achers - rrect, above all, following code rules, although during the grades justification they refer to textual ascuraive information, conveying that they have acquired a modern theoretical discourse followed by a traditi, $r$ actice

Keys-world: Assessment, textual production, in the on ae, teacher trainung.
\end{abstract}

\section{INTRODUÇÃO}

Tradicionalmen ${ }^{\dagger}, c_{\text {s. }}$ pete ao professor de língua materna ensinar seus alunos a ler e escrever. Para iss , ba ca 'o em seus conhecimentos conteudísticos e didáticos, ele lhes propõe atividad a versif cadas de leitura e escrita, que são corrigidas tendo em vista o parâmetro ec abele ‘ do: o "português correto". Esse quadro escolar passou a ser questionado, há duas uéca las, aproximadamente, considerando-se dois aspectos: o primeiro (cronc og camen. a) foi o conceito de "português correto" e o segundo, a partir da última décau ' f 1 a ormação de professor. Por influência das ciências da linguagem, a concepção - língu. como um código homogêneo, cristalizado e neutro, foi reconsiderada e, à luz de o "tr o s ontos de vista, língua passa a ser concebida como um conjunto de variações que se eft iva na interação entre sujeitos (logo, questiona-se a existência do "português correto", in abstracto). A formação de professores, por sua vez, enfatizando a homogeneidade da língua e conhecimentos teóricos desvinculados da experiência profissional, não possibilita ao professor estabelecer uma relação entre o conhecimento teórico que recebe da universidade e sua prática cotidiana.

${ }^{1}$ Esta análise faz parte da pesquisa Práticas de Escrita e de Reflexão sobre a Escrita em Contextos de Ensino, projeto integrado CNPq/UNICAMP/UFCG (proc.520427/2002-5 NV). 
BEZERRA, QUEIROZ \& TABOSA - Correção de textos e concepções...

Considerando esse contexto e nosso trabalho com formação básica e continuada de professor, realizamos este estudo sobre correção e avaliação de textos escolares, efetivada por professores de língua materna, em situação de formação continuada (freqüentando um curso de especialização). Nossos objetivos são identificar conceitos de língua e variedade lingüística subjacentes a essa atividade didática; e explicitar a relação existente entre esses conceitos e a correção/avaliação.

Nosso interesse em analisar essa atividade didática deve-se ao fato de que ela se constitui num trabalho docente constante, que deve refletir os princípios nortead ores i? projeto didático-pedagógico da escola e que, muitas vezes, não foi objeto de e tudo na formação dos professores.

Para melhor demonstrar como foi realizado nosso estudo, dividimos o, resent artigo em três partes, além desta introdução: 1) descrição dos passos metodológ ‘ os paı a otenção dos dados de análise; 2) apresentação de princípios teóricos fundamen tai cunálise; e 3 ) análise de dados e conclusões.

\section{PROCEDIMENTOS METODOLÓGICOS}

Este estudo segue o paradigma qualitativo $\mathrm{p}_{\mathrm{A}}$ uisa, pois procuramos interpretar os dados coletados, considerando a teoria pertir en e a e $\lambda_{\curlywedge}$ eriência dos sujeitos da pesquisa. Esses são 12 professores de Língua Portug èsa do e. sino fundamental e médio, graduados em Letras, por duas universidades públi as ( ma estadual e outra federal), há no mínimo 01 ano e, no máximo, 12 anos, com e re rié cia ocente variando entre 01 e 14 anos, como está descrito do quadro 1 abaixo. dif ca entre o tempo em que estão graduados e na docência foi considerada para a anáı e realizada, pois interessava-nos verificar como os conhecimentos conceituais n neriencrais interferem na atividade de correção/avaliação.

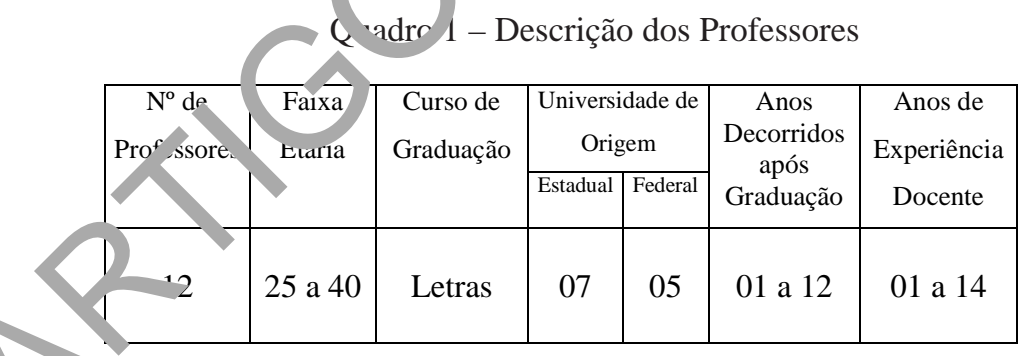

Esses professores freqüentaram o Curso de Especialização em Lingüística Aplicada ao Ensino de Língua Portuguesa², com duração de 360 horas, oferecido pelo Departamento

\footnotetext{
${ }^{2}$ Disciplinas oferecidas pelo Curso: Tópicos de Sociolingüística (45 horas); Tópicos de Lingüística Textual (45 horas); Metodologia da Pesquisa Aplicada ao Ensino de Língua (60 horas); Metodologia do Ensino de Literatura (30 horas); Teoria e Prática de Leitura (45 horas); Teoria e Prática de Escrita (45 horas); Tópicos de Gramática (45 horas); e Análise e Preparação de Material Didático (45 horas).
} 
de Letras da Universidade Federal de Campina Grande, entre os meses de janeiro de 2002 e fevereiro de 2003, na cidade de Campina Grande (Paraíba).

A disciplina Análise e Preparação de Material Didático, a última do curso, teve como objetivos (1) avaliar material didático de língua portuguesa destinado ao ensino fundamental e médio, à luz das tendências da Lingüística Aplicada para o ensino de língua materna, e (2) preparar material para o ensino dessa língua, considerando a Lingüística e a Gramática. Como conteúdo específico foram estudados, entre outros, tópicos sobre concepções de linguagem, objetivos do ensino de língua portuguesa e avaliação de atividades e ta ctas se ensino de leitura, escrita e gramática.

Entre o conjunto de atividades relativas a esse último ponto (avaliação a c tiv dad s e tarefas de ensino de leitura, escrita e gramática), foi realizada uma co reção le dois textos escritos por um aluno (em séries diferentes), cujo objetivo e obse var até que ponto as leituras e discussões efetivadas durante todo o curso, a so ndas às suas experiências, poderiam estar influenciando os professores na ta fa de c rrigir textos. $\mathrm{Ou}$ seja, que conceitos e procedimentos eles estariam mobilizando ao in erferirem no texto do aluno. As principais leituras feitas pelos professores sobre n reção/avaliação foram de Perrenoud (1999), Elizabeth Marcuschi (2001), Serafini (19 \%), Evangelista et al. (1998) e Ruiz (2001).

Aos professores foi solicitado o seguinte: Tria redações abaixo, escritas por um aluno na $\sigma^{a}$ série do ensino fundamental $e, d-p$ is, na ${ }^{a}$ do ensino médio, corrija-as e atribua-lhes uma nota. Diga e explique e $\hat{A}$ que vu ê está se baseando para fazer essa correção. A atividade foi realizada na pr wri sala de aula, durante aproximadamente uma

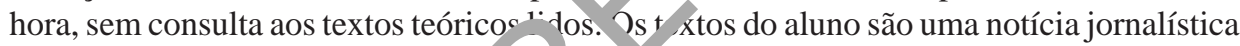
e um parágrafo narrativo-descriti a, es - in es situação de prova bimestral (ver item 6, análise dos dados). Os resultados des ₹ correção são justamente os dados de análise deste trabalho que ora apresentar os.

Abordaremos, a segu r, a forı ação de professor e a correção/ avaliação, apenas naquilo que se relaciona diret an cor nossos dados.

\section{FORMA'Á 'E PROFESSOR}

TO. mação de professor, por influência da pedagogia tecnicista da década de 70 do

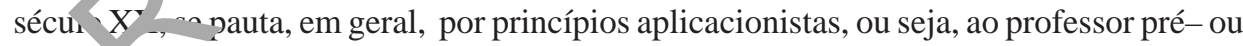

servı o é ensinado que aplique um determinado método de ensino, utilize certas técnicas, p ra zuantir a aprendizagem dos alunos e o sucesso do ensino. Dessa forma, parte-se de als Ins pressupostos, às vezes não conscientes: língua é código, que funciona de maneira homogênea e independente dos interlocutores; aprendizagem ocorre de forma passiva, sendo necessária apenas a imitação de modelos; e ensino se dá pela exposição oral dos conteúdos de cada série aos alunos que, ao ouvirem/verem, vão registrando essas informações em sua memória.

O surgimento de outros pontos de vista, a partir dos anos 80-90, acerca da linguagem (cf. Bakhtin), do processo ensino-aprendizagem (cf. Vygotsky) e das representações do mundo objetivo, social e subjetivo que se tem para interagir, entender, transformar os 
BEZERRA, QUEIROZ \& TABOSA - Correção de textos e concepções...

contextos onde se atua - o agir comunicativo (cf. Habermas), influenciando a formação de professores, vem provocar uma alteração no conceito de "formação de professor", que pode ser entendido como a articulação de dois componentes curriculares: conhecimento teórico e conhecimento de ensino e de pesquisa sobre ensino (Reinaldo, 2001).

A ênfase no conhecimento teórico vem desde a criação dos cursos de licenciatura (na primeira metade do século XX), mas agora numa perspectiva diferente: procura-se dar ao futuro professor ou professor condições para que ele se posicione diante da pluralidade de estudos sobre a língua e reflita criticamente sobre fatos lingüísticos.

O conhecimento de ensino e de pesquisa sobre ensino, segundo Reina do (op

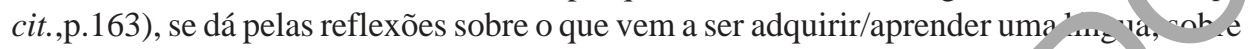
as capacidades e os fatores individuais ou coletivos (de ordem cognitiva, ar tiva ou social) que interferem no processo de aprendizagem de uma língua; o papel do $r$ e se cu v $\mathrm{r}$ icionou chamar de erro e das correções nesse processo evolutivo do aprenc i : a efeito que determinados procedimentos de ensino formal no tratamento $s^{\prime}$ certas questões podem provocar na aprendizagem e no desenvolvimento do educando.

Esse componente, ainda segundo a autora (op. cit.), le a nrofessor pré-serviço e em serviço a uma reflexão crítica sobre seu próprio trabalho, de vo a desenvolvimento de uma atitude de pesquisa em relação à sua prática d $r$ cent - qu lhe possibilitará ver a sala de aula não como o lugar da certeza, ou de aplic đçầ e um conhecimento acabado, mas como um espaço de busca do conhecimento. T d t -se do nodelo de formação do professor chamado por Wallace (1991, apud Mat'ss, 2002 de "modelo reflexivo", com duas dimensões principais: o conheciment re ebido, na forma de saber científico, e o conhecimento experiencial, relativo a pe ên c a profissional. O primeiro se constitui de informações e teorias relacionada a a g $\mathrm{g}$ ' $\mathrm{m}$ upo de pesquisa e que são encontradas nos programas de formação; o segundo e constitui no saber tácito que o professor adquire como consequiência natural u va prátıca competente da profissão. Modelo que, explicado de outra forma, é defendic o por T، rdif (2002), quando afirma que a crença na formação de professores, associad r rin inalr ente à sua atividade cognitiva ou intelectual, não resulta positivamente se 1 ão 0 - $\mathrm{m}$ considerados os saberes dos professores, produzidos socialmente.

Nessa erspe tiva e que analisamos as correções feitas pelos professores, tentando explicitar a as ciaçâo entre seus conhecimentos conceituais e experienciais.

\section{CON TEITOS DE CORREÇÃO E AVALIAÇÃO}

Como foi citado o arcabouço teórico lido pelos professores (item 2), que fundamentou sua correção, fazemos aqui um resumo das principais contribuições teóricas, a fim de nos esclarecer na análise dos dados.

\subsection{Correção}

Corrigir é intervir no texto do aluno, a fim de adequá-lo a normas lingüísticas e textualdiscursivas. Trata-se de uma atividade complexa, que varia de acordo com o gênero textual, 
seu objetivo e seu escritor (sua formação e experiência), não sendo, portanto, capaz de se proceder a esta atividade de forma mecânica, dentro de modelos pré-definidos.

Serafini (1989:108-112), em seus estudos sobre correção, expõe seis princípios que considera indispensáveis a esta prática: a) a correção não deve ser ambígua (o que precisa ser mudado, na opinião do professor, deve estar bem explicitado); b) os erros devem ser reagrupados e catalogados (uma forma de se proceder à classificação dos erros, especificando seu tipo); c) o aluno deve ser estimulado a rever as correções feitas, compreendê-las e trabalhar sobre elas (a concepção de que escrever é um processo c sntı̆n ? que envolve reescrituras deve ser enfatizada entre os alunos); d) deve-se corrigi pouco. erros em cada texto (evitar abordar muitos pontos que necessitem de reparos ocm tempo, porque esta atitude pode desestimular o aluno-escritor); e) o profe sor de e estar predisposto a aceitar o texto do aluno (deve ter uma postura receptiv sem $\mathrm{p}$ es nnceitos em relação ao tema, à linguagem, ao estilo etc. escolhidos pelo aluno); $\mathrm{f}$ ) ( v r reção deve ser adequada à capacidade do aluno (apontar apenas pontos qv - o alun tem maturidade para corrigir).

Esses princípios levam o professor a proceder de mo to diferentes com o texto do aluno, resultando formas de corrigir diversas, que essa mes autora (op. cit.) classifica como: a correção indicativa, na qual são marcados a pal vras as frases e os períodos que parecem pouco claros ao professor (ficando o $a^{1} \mathrm{Ano} \mathrm{m}$ a difícil tarefa de inferir o que errou); a resolutiva, que consiste em corrigir to $\mathrm{AO}$ os erru reescrevendo o que se considera incorreto (eliminação do erro pela solu âo que eflete a opinião do professor); e $a$ classificatória, na qual se corrigem os " ros" classificando-os segundo seus tipos (se são de origem sintática, se dizem respei $\leadsto$ or ora ora $^{\prime}$, à pontuação etc).

Complementando essa classi ' cac o, Rurz (2001) propõe um quarto tipo de correção: a textual-interativa, intervenção rea zada sempre nos espaços em branco (que não são nem o corpo, nem as mar ori do texto do aluno) do texto corrigido. São espécies de bilhetes ou cartas escritas elo pro essor, ou para reforçar positivamente a tarefa realizada, ou para cobrar algo ona fico claro durante a atividade. Este quarto tipo de correção, segundo a autora, c nse a nreencher e/ou complementar as lacunas deixadas pelas outras formas de corri ̨ $r$ u $\urcorner$ text , acima expostas, já que estabelece comunicação direta com o aluno-escrit $i$, cria. do oportunidades de maior participação deste nas observações do seu texto. O que a. 'erencra esta proposta de correção da anterior é o seu caráter especialmente interat vo.

$\mathrm{Pu}^{+}$a p s sição relativa à correção de textos escolares vem-nos de Evangelista et al. 1998), 'gundo as quais, há duas formas de olhar, ou "reparar" o texto do aluno. A primeira, a 'ot a. por professores que vêem a língua como código, corresponde a uma perspectiva no mativo/prescritiva. Para estes, o conhecimento de regras gramaticais é indispensável ao desenvolvimento das habilidades de leitura e escrita; conseqüentemente, o texto do aluno serve apenas de instrumento de verificação e aprendizagem de tópicos gramaticais. Porém, não se estimula o aluno a ler o seu próprio texto e refletir sobre suas falhas. Daí a afirmação dessas autoras (op. cit., p.16) de que, na tradição escolar, a avaliação tem se orientado pela busca de erros gramaticais.

A segunda forma, adotada por professores que vêem a linguagem como processo de interação, corresponde à perspectiva dialógica da língua. Para esses, o domínio da língua 
não depende exclusivamente do conhecimento de regras gramaticais, mas da relação destas com as regras pragmáticas e discursivas envolvidas no processo de comunicação. Neste caso, o primeiro passo para corrigir-se o texto do aluno é o estabelecimento de um "jogo interlocutivo", cuja prioridade é a busca de sentido do texto. Interessa, portanto, ao professor, observar a correspondência da produção do aluno com a proposta solicitada, o que o aluno tem a dizer e ainda de que estratégias ele se utiliza para dizer, atentando-se, sobretudo, para a inter-relação forma, conteúdo e contexto.

Assim, durante sua prática pedagógica, o professor não privilegia um tipo es ecin ? de correção em detrimento de outro, visto que todos têm seu grau de importâ cia e ș complementam mutuamente. O que ele deve fazer é realizar sua correção de ran ira clar a, sem ambigüidade, para que o aluno possa realmente entender o que precisa ser me horado no seu texto. Além disso, este professor precisa ser o co-autor (Ruiz, $C$ cit.) 'o t xto que corrige e não apenas um observador que realiza apenas correções locai es $\mu_{\Lambda}$-rficiais sem considerar o texto em seus aspectos temáticos e composicionais, ntos ta nbém essenciais.

\subsection{Avaliação}

Observando a avaliação de modo amplo, é váli a at rma que ela não é um fim em si mesma, mas um julgamento que aponta um camir o $\mathrm{p}$ a o furicionamento didático. Assim, a avaliação não deve fazer parte apenas do je so interlo, ytivo que se joga na escola, mas deve ter a força de renová-lo e reorientá-lo Aeixana de ser uma atividade negativa para se tornar um momento privilegiado de se re er $\mathrm{c}$ processo ensino-aprendizagem (Evangelista et al., op. cit., p.16).

Tendo as mesmas idéias acir a, P n noud (1999) propõe a avaliação formativa em oposição à classificatória (ou nor ativa), cujo objetivo principal é hierarquizar as capacidades, tomando-se o vim base de sucesso ou de fracasso a nota conseguida pelo aluno. Nessa concepção, a avaliaç o é vista com um fim em si mesma, desvalorizando, por

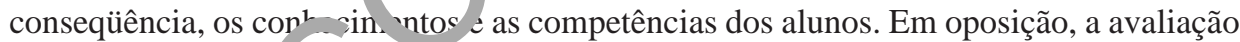
formativa enfoca a prer al agem individual de cada aluno; tem a preocupação de observar como andam as ap. cidad s desse aluno, tornando-se, assim, uma estratégia pedagógica de luta cont a o fro asso e as desigualdades (Perrenoud, op. cit., p.18) dentro da escola.

Lüdke \& Mediano (1992), em estudo realizado em escolas da zona sul do Rio de Janeir , $a_{1}$ ontam a existência de dois tipos de avaliação. O primeiro é aquele que coloca o profo so $\mathrm{CO} \supset$ o detentor do saber, transmissor único do conhecimento, e por isso toma o ' no co no ser passivo do processo de aprendizagem; e o segundo, aquele que vê o professor c $m$. mediador da aprendizagem do aluno, o qual passa a ser um agente ativo nesse pr cesso (posturas idênticas às citadas por Evangelista et al., op. cit.). Embora havendo esses dois tipos de conceber a avaliação, em geral ela é (segundo as autoras) subjetiva e sem critérios bem definidos.

Retomando Serafini (op. cit.,p.130), citada anteriormente, essa autora afirma que a avaliação tem algumas funções, que podem orientar o trabalho do professor: a função de mensuração, na qual um texto é avaliado em comparação a outros; a preditiva, que avalia o futuro desempenho do aluno; e a de pesquisa, que observa o progresso das capacidades do aluno em determinado espaço de tempo. 
Para que esta prática seja bem sucedida, esta autora sugere que se leve em conta as diversas fases de desenvolvimento dos alunos; o objetivo dado ao texto no momento de sua produção, a fim de direcionar uma possível correção e avaliação do texto;o gênero utilizado, uma vez que as normas para a construção de um texto, em determinado gênero textual, podem influenciar o momento de sua avaliação; e o tipo de estímulo oferecido para se iniciar o processo da escrita, uma vez que a boa produção dependerá diretamente do embasamento dado pelo professor, influenciando na produção e, conseqüentemente, na avaliação.

Essa perspectiva é criticada por Evangelista et al. (op. cit.), ao afirmarem qu reduzi a avaliação de textos a um conjunto de procedimentos a ser rigidamente cgu cor a uma atitude simplista (p. 16). Assim, enquanto Serafini se propõe a estabele er para ligmas de avaliação, Evangelista et al. (op. cit.) defendem a idéia de que ravalias ão pode se apresentar sob formas e momentos diversos. Nessa perspectiva, aval ar se significar corrigir, reescrever, rascunho, passar a limpo, confirmar, ou r ar hi, óteses no ato da escrita, o que não precisa ser necessariamente realizado apenas a chamada 'aula de redação' (p.17).

Aqui, o que cabe ao professor é ter conhecimento d Avanação como um ponto importante do processo de aprendizagem e não cop 0 o c hiet o deste processo. Realizar um balanço das anotações coletadas durante a corr ção esclarecer os critérios privilegiados é indispensável para uma prática coerente e c e raz res.ltados. $\mathrm{O}$ aluno precisa entender o que foi feito no seu texto, para que ele $\mathrm{p}$ ssa pass $r$ à etapa seguinte e dar continuidade à sua aprendizagem.

\section{CONCEPÇÕES DE LÍNGUA E VARIAÇÃO LINGÜÍSTICA}

As ciências da lingı agem, or olharem o objeto linguagem humana de pontos de vista diferentes, têm cur tri 'ído ara o conhecermos de formas variadas. Ao propor-se seu estudo do ponto de vist? a enunciado ou da enunciação, abre-se, como todos sabem, um leque amplo de co cepçr̃ es, que tem repercussões no ensino de língua (materna ou estrangeira) na esc la basica.

Não ob, tivo nosso, neste tópico, apresentar o estado da arte em relação aos estudos desen olv dos soure concepções de linguagem, mas apenas retomar alguns conceitos mais difun id $s$ qu têm relação direta com a variação lingüística, pois esses pontos nos ajudaram analisa nossos dados.

N radição gramatical concebe a língua como uma abstração ${ }^{3}$, uma essência, um ideal isc ado, independente do povo que a fala, influência da filosofia platoniana, que pregava que as Formas só podem ser captadas pelo intelecto, não pelos sentidos. Sendo uma abstração, não muda nem varia e é vista como ideal da perfeição a ser atingida. Essa concepção remete para o que se convencionou chamar de língua culta, que a escola deve

${ }^{3}$ Não desconsideramos a existência de objetos intelectíveis e sensíveis. Reconhecemos a diferença entre língua como objeto intelectível (construção do especialista) e língua como objeto sensível (linguagem em uso). No entanto, a língua como objeto intelectível não se presta completamente ao trabalho escolar. 
ensinar, embora não se saiba exatamente qual é essa língua culta. Com esse objetivo e influência remota da filosofia platoniana, via compêndios gramaticais, a escola se especializa em ensinar as classes e categorias gramaticais para que o aluno se aproxime dessa abstração que é a língua.

Essa concepção de ensino de língua presente na maioria das escolas, reforçada pelo senso comum e pela mídia, é resultado de uma série de reduções - língua = norma culta $=$ gramática da frase - (Bagno,2002), que torna cada vez mais distante o falante real (aqui o aluno) dessa língua ideal.

Entretanto, se deslocarmos nosso olhar desse ideal para o real, saindo do tbstratc

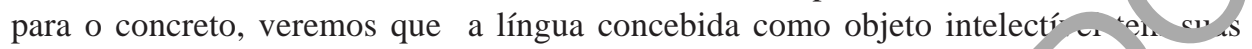
limitações no âmbito das atividades de ensino, pois a ênfase aqui deve rec ir sobi : o uso lingüístico efetivo (para desenvolvimento da competência comunica va do al hos), já que o que existe, nesse contexto, são os sujeitos que a falam, impriminc - cr ma série de variações que são construídas numa realidade histórica, social ultura Ou seja, é uma atividade social, no dizer de Bagno (op. cit.), que se realiza sempre qu os falantes interagem verbalmente. Dessa forma está sujeita às vicissitudes hun in. daí suas alterações, sua opacidade, suas variações. É levando em conta a línøua ce ro um objeto sensível, que fazemos as afirmações seguintes.

Tomando emprestado assertivas encontrad is o Maruschi (2000:20), citamo-las aqui, para verificarmos como a concepção tre $\Lambda_{1}$ ional a. língua é reducionista:

a) A língua apresenta uma organi. nçã interna sistemática que pode ser estudada cientificamente, mas ela não se redu7 a m c nj v ito de regras de boa-formação que podem ser determinadas de uma vez por das a no se fosse possível fazer cálculos de previsão infalível. As línguas naturais são difı Imente formalizáveis.

b) A língua tem aspe cov estáveis e instáveis, ou seja, ela é um sistema variável, indeterminado e não fixo. Portant , a língua apresenta sistematicidade e variação a um só tempo.

c) A língua se dete $\mathrm{n}$ ina por valores imanentes e transcendentes de modo que não pode ser estuda 'a a form 1 autônoma, mas deve-se recorrer ao entorno e à situação nos mais variadr s cont vtos de uso. A língua é, pois, situada.

d) Aríng - a constrói-se com símbolos convencionais, não aleatórios mas arbitrários. A líng a $\mathrm{i}$ ão é un. fenômeno natural nem pode ser reduzida à realidade neurofisiológica.

) A1r. ya não pode ser tida como um simples instrumento de representação do

ndo - vmo se dele fosse um espelho, pois ela é constitutiva da realidade. É muito mais u $\mathrm{r}$ c an do que um espelho da realidade.

f) A língua é uma atividade de natureza sócio-cognitiva, histórica e situacionalmente desenvolvida para promover a interação humana.

g) A língua se dá e se manifesta em textos orais e escritos ordenados e estabilizados em gêneros textuais para uso em situações concretas.

h) A língua não é transparente, mas opaca, o que permite a variabilidade de interpretação nos textos e faz da compreensão um fenômeno especial na relação entre os seres humanos. 
i) Linguagem, cultura, sociedade e experiência interagem de maneira intensa e variada não se podendo postular uma visão universal para as línguas particulares.

Esse conjunto de informações contribui para reconhecermos que a língua é sistemática e variável, imanente e transcendente, constrói-se com símbolos convencionais e arbitrários, não naturais, não representa a realidade, mas é constitutiva dela, é de natureza sóciocognitiva, histórica e situacional, se manifesta em textos orais e escritos, estabilizados em gêneros textuais, permite variabilidade de interpretação, não podendo se prende a un a visão universal. Ou seja, uma língua particular não se deixa reduzir a uma só va iedade nem se define de forma apriorística, isolada de uma situação ou dos falante

Nessa concepção de língua que promove a interação humana, as variaç es são características inerentes à própria língua: variação de espaço, de $\backsim$ mpo, de grupo e individual. Em outras palavras, mudanças, variações e registros. Muc nc as a longo do tempo, do ponto de vista diacrônico; variações em uma mesm noca, o ponto de vista sincrônico (variações geográficas e sociais); e registros, do ponto is vista do falante em relação à situação comunicativa (os vários registros que av do mars informal ao mais formal).

\section{INTERVENÇÃO DOS PROFESSOREY N TS TEYTOS DO ALUNO}

Com base no referencial teórico e no $\hat{\jmath}$ anteriormente, analisamos nossos dados, iniciando pela descrição das redaçõ $\rho$ olic $\operatorname{tad}$ o. Os textos corrigidos foram escritos em situação de prova bimestral (como oi d wo no item 2), momento em que se espera do aluno demonstrar seu conhecimento relativo oos tópicos estudados. O texto 1, apresentado abaixo, foi redigido quando o aluno sta a na $6^{\mathrm{a}}$ série do ensino fundamental de uma escola particular (em um bimestre cujo c nteúdo incluía o estudo de textos jornalísticos) e atendia ao enunciado:

Redija uma p quer a otícia com a seguinte manchete:

\section{ALÔ V JCÊ: VOVAS ATRAÇÕES NO MAIOR CARNAVAL FORA DE ÉPOCA}

ros. Lemb. e-se das três partes que compõem uma notícia. A manchete você já tem, rir o l. de e o corpo da notícia (mínimo 6 linhas).

bloco Alô você vai trazer para Campina Grande varias atrações como a banda Araketo, Fernando Vanuci e muitas outras. Vai sair na Quinta-feira, começa no SPAZZIO e termina no PARQUE DO POVO onde a folia vai estar solta.

A precisam da prefeitura foi construir esse bloco pois muitas pessoas famosas vinheram para eles ficarem juntos construíram o bloco que ai o trouxeram o Araketo e fizeram o bloco que vocês vem

$$
\text { ALÔ VOCÊ }
$$


BEZERRA, QUEIROZ \& TABOSA - Correção de textos e concepções...

O texto 2 , a seguir, foi escrito quando o mesmo aluno estava na $1^{a}$ série do ensino médio de outra escola particular (em um bimestre cujo conteúdo era narração, descrição e dissertação) e atendia ao enunciado:

Mostre, num parágrafo narrativo-descritivo, as marcas de narração e as de descrição.

\begin{abstract}
A professora Lúcia dos Santos foi morta com 3 tiros em frente a sua casa ontem na Rodrigues Alves às 7 horas da noite. Lúcia tinha saído da escola, onde dá aula, dois homens armados abordaram e pediram sua bolsa. Lúcia não quis entregar e saiu correndo e gritando, para que he salvasse então os dois homens começaram a tirar e 3 tiros a acertaram-na dois nas costas e un na nuca e fugiram, e Lúcia morreu na hora.
\end{abstract}

Nos dois enunciados, o que está sendo enfatizado é a estrutura espera $n-c$ textos curtos: o corpo da notícia com pelo menos 6 linhas e o texto 2 con ur a arágrafo. $\mathrm{O}$ comando para a escrita do texto 1, embora não apresente o ter, gêne 0 , na verdade já traz subjacente a perspectiva teórica de gêneros, uma vez que está sen 'o solícitada a redação de uma notícia jornalística, mas a ênfase é apenas no se mponente composicional (manchete, lide e corpo da notícia); o texto 2 enfatiza a i ologia clássica (narração, descrição, dissertação), especificamente o aspecto estrı tura (marcas da narração e da descrição). Considerando essas informações no p spn nunciado da questão, percebemos que a correção/avaliação dos textos será orien a pelo a endimento total ou parcial de sua forma.

Verificando de que modo os profes ore corrigiram os textos, vemos que $24 \%$ deles reescreveram-nos, corrigindo suas fal a rela iva ao conteúdo e forma (correção resolutiva); $12 \%$ apenas indicaram as falhas g. mat $\ldots$ is (numa correção indicativa); e 64\% indicaram e classificaram os erros nos textos, su ruindo a proposta de correção de Serafini (op. cit.). Desses 64\%, 25\% recorrer .11. mbém a correção textual-interativa (cf. Ruiz, op. cit.)..

Exemplo 1

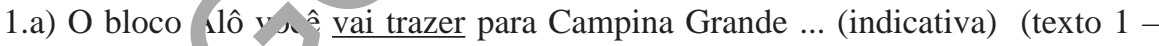
prof.. )

1.b) A rofes ra Lúcia dos Santos foi morta com 3 tiros em frente a sua casa ontem - A rofessora Lúcia dos Santos foi morta ontem com 3 tiros, em frente a sua casa... (resolutiva) (texto 2 - prof.4)

c) Po tuação - você está introduzindo uma informação nova, que se refere ao surgimento do bloco, por isso deve usar um sinal de pontuação adequado. (textualinterativa) (texto 1 - prof.3)

Mais da metade dos professores (64\%) corrigiu os textos seguindo informações teóricas advindas das leituras realizadas no curso de especialização, ou seja, indicando e classificando os erros; o que significa uma postura de reflexão sobre o texto do aluno, com o intuito de orientá-lo a tomar outras decisões sobre seu texto. Difere de uma correção automática, com eliminação de todas as falhas, mas sem exigir do aluno uma releitura de sua redação.

As notas atribuídas ao texto 1 variaram de 6,0 a 8,5 e ao texto 2 , de 7,5 a 10,0. Observando apenas essas notas, vemos que o texto 2 foi considerado melhor do que o texto 
1 (a média das notas ficou em 7,3 e 8,5, respectivamente).Quando analisamos as justificativas para essas notas, vemos que há algumas incompatibilidades em relação à linha argumentativa do professor e ao peso dado às falhas apontadas.

Exemplo 2

2.a) Apesar das informações apresentadas sobre o que foi solicitado no enunciado da proposta da atividade, o texto contém algumas inadequações com relação ao aspecto formal (acentuação e pontuação) como também, não apresenta claro. a e articulação de algumas idéias (...) Dessa forma, a nota $(6,0)$ atribuída o texto justifica-se pelas informações e pelo texto corresponder ao que f or o lin itads, mas também a falta de coesão (...). (texto 1 - prof.3)

2.b) Analisamos no texto 2, que a aluna conseguiu construir texto or orme a proposta apresentada. Houve um encadeamento das idéias cl a a nos fatos narrados. Por isso, a nota $(7,5)$ foi atribuída por e, a alun ter conseguido desenvolver o seu texto mostrando conteúdo de forma rganızada. (texto 2 prof.2)

Em 2.a, a primeira parte do texto (antes de ser atrib rída nota) leva-nos a crer que, por falhas gramaticais e falta de clareza e artic iaça de argumas idéias, a nota vai ser baixa. Na segunda parte, quando é dita a nota, 0 , ר), o pı fessor justifica-a, argumentando que as informações sobre o tema foram ${ }^{\prime}$ ddas, qu há adequação ao que foi solicitado (aspectos positivos), mas falta coesão (a nec $o$ negativo). Assim, aparentemente, não fica claro para o leitor porque essa nota, co sid iando o conjunto do texto deduz-se que o argumento prevalecente é o das fa nas acorma.

Em 2.b, os argumentos apresenta os (adequação ao solicitado, encadeamento de idéias, clareza nos fatos narrados cơ teúdo apresentado de forma organizada) nos levam a crer que a nota será alta, mas é, 5, a m، is baixa atribuída a esse texto. Não foi indicada nenhuma falha para tal nota, em ${ }^{k}$ a, o pró rio texto do aluno, haja correções indicativas e resolutivas para itens do códig, line at tico.

Interpretai os sse $\mathrm{p}$ ocedimento como resultante de conhecimentos conceituais a que os prof $f$ sores tiveram acesso (coesão, coerência, adequação entre o solicitado e o realizado...) e ' 'as experiências docentes, marcadas pela tradição (ênfase na gramática da palavr $\mathrm{mr}$ se). Is o faz o peso das falhas gramaticais ser maior e, consequientemente, a nota aiy ar.

Do conjunto dos professores, apenas um - o que havia concluído o curso mais r ce' ' nente e com menos tempo de experiência de ensino (um ano) - propõe a reescrita do exto, para, em seguida, ser dada a nota. Ou seja, o trabalho de correção é visto como uma interlocução com o aluno, orientando-lhe a refazer o texto, para adequá-lo tanto ao gênero, ao tema, quanto à forma, de acordo com o proposto por Ruiz (op. cit.), citada nos pressupostos teóricos.

\section{Exemplo 3}

O comentário escrito no final do texto solicita ao aluno a rever sua produção, observando os apontamentos efetuados pela professora para posterior reescrita do 
BEZERRA, QUEIROZ \& TABOSA - Correção de textos e concepções...

texto. (...) Quanto à atribuição da nota será efetuada na última versão, segundo alguns autores a atribuição de notas na primeira versão pode comprometer um trabalho de releitura, revisão e reescrita do texto proposto. (textos 1 e 2 - prof.7)

Embora tenha sido bastante discutido no Curso de Especialização que fosse dada ao aluno a oportunidade de reescrever seus textos para adequá-lo ao solicitado e se apropriar de modelos de escrita compatíveis com os gêneros textuais, o professor do exemplo 3 não levou em conta que esse texto foi escrito numa situação de prova, sem oportuni ade uma refacção. Talvez, pelo pouco tempo de experiência docente e pelo fato de 1 abalha numa escola pública que tem cultura diferente daquela de escola particular $\mathrm{Or} \mathrm{Xu}_{\mathrm{nn}} \mathrm{s}$, dá mais flexibilidade ao professor para escolher sua metodologia), o vrofes or não considerou a cultura da escola particular (por exemplo, a entrega da notas, or Los dias após a aplicação da prova). Esses são saberes docentes que vão sendo or o 'uídos com a experiência cotidiana, ou seja, vão sendo produzidos socialme e, con 5 defende Tardif (op. cit.).

\section{CONCEPÇÃO DE LÍNGUA E VARIAÇÃO J NG TíS ICA SUBJACENTE À CORREÇÃO}

Comparando o tempo de experiência Aocente om a correção feita, observamos que os professores mais antigos são os que cor ger $\mathrm{o}$ texto considerando-o um produto acabado: o aluno fez sua versão e o profess o prr ¿ e-a eformulando todas as partes que forem necessárias, segundo seu entendir ento

\section{Exemplo 4}

Corrigi principalme te o as ecto semântico. No lide especificando os elementos da notícia e no corr.es "itur ido as frases de forma a evitar o truncamento de idéias que dificultov a co $\Lambda_{\mathrm{K}}$ reensão, principalmente do $2^{\circ}$ parágrafo. (prof. 1 - texto 1 )

Após f se co nentario, segue-se o texto refeito e sem nota. Ou seja, o professor, lançando não le uma correção resolutiva, demonstra entender a língua como um conjunto de reg as, que o a uno aprenderá se for observá-las. Assim, a língua é transparente e pode ser e ud da te forma autônoma, independente de contextos de uso. O professor refaz o vto do qluno, ele o lê e "aprende" como escrever melhor, sem nenhuma negociação ou c $m$ in rio entre professor e aluno.

As observações feitas nos textos do aluno e, em seguida, a explicação para a nota dada levam-nos a perceber que a maioria dos professores $(88 \%)$ concebe a língua (pelo menos nesses dados) como a tradição gramatical: conjunto de regras e classificações abstratas a serem aprendidas para uso posterior. A idéia de língua como atividade social, de que fala Bagno (op. cit.), através da qual os falantes interagem, parece não ser defendida por eles e as variedades lingüísticas que vão sendo utilizadas conforme as situações não são consideradas pelos professores. 


\section{Exemplo 5}

O texto $\mathrm{n}^{\mathrm{o}} 1$ apresenta, no primeiro parágrafo, o nome da cidade onde ocorrerá o evento, o nome do bloco, atrações, o local de concentração, o lugar onde termina a festa e ressalta que as pessoas vão se divertir. Há a necessidade de acentuar a palavra "várias", faltou destacar o $2^{\circ}$ nome do bloco em inicial maiúscula "Alô Você". O dia da semana, "quinta-feira", deve estar escrito em inicial minúscula porque é substantivo simples. (texto 1 - prof.4)

Ao enfatizar, apenas, esses elementos de ordem microestrutural do código (ace ituação letra maiúscula e minúscula), o professor despreza outros aspectos do texto qu o n n lac direta com a situação de comunicação: trata-se do gênero notícia jornalístı q, que em um objetivo comunicativo e para ser escrito leva-se em conta aspectos temáti ns, con no cionais e estilo. E o texto em questão não apresenta apenas falhas de acen ua a ortografia, pontuação, demonstra que o aluno não aprendeu ainda à escrever ma no، cia, mesmo num nível elementar (não se trata de curso de jornalismo), imprimindo ao texto muito mais características de redação escolar do que desse gênero jor à ctico (por exemplo, o final do texto com o início do título repetido e o uso da palavra $\mathrm{F}_{\text {, }}$ ).

Em relação à variação lingüística, o que se obs -rva que não há lugar para ela. Visto que os textos foram solicitados em contexto de $\varepsilon$ kan $c$ a tradição escolar se volta para a aprendizagem do registro formal, os professe es os cor giram sem fazer nenhuma alusão à variedade lingüística, mas apontando tr cas de p lavras ou expressões, para ajustar o texto ao modelo padrão.

\section{Exemplo 6}

No texto $\mathrm{n}^{\mathrm{o}} 2$, o aluno consegu r relatar o fato, mas há problemas de repetição de palavras que podem sf su'stituídas por anafóricos, como está destacada na correção. Seria importante a presen a do advérbio "ontem" no início do texto porque contextualiza, $m$ is r $r$ nidar ente, a data do acontecimento. Sugeri uma substituição ou modificaçî 0 da ic e: "para ir para casa e ela sempre vai a pé" por "e voltava para casa a pé, \m semr re fazia” para que a notícia ficasse mais coerente. (texto 2 prof. 4

s 1 terven form. ' ( $r$ ara 'r para casa e ela sempre vai a pé por e voltava para casa a pé, como sempre f - $\mathrm{i} i$ ), a 'esar de ele ter escrito ficar mais coerente, o que remete ao sentido e não ao r gic . Esse procedimento pode ser interpretado como explicitação de que o professor se propriou de princípios teóricos sobre texto (coerência, anáfora e outros), mas não os mobilizou de forma adequada, ao fazer sua correção, pois lançou mão de critério de textualidade (coerência) por registro lingüístico (formal/informal). 
BEZERRA, QUEIROZ \& TABOSA - Correção de textos e concepções...

\section{CONSIDERAÇÕES FINAIS}

Os dados analisados permitem-nos inferir que a atividade de corrigir e avaliar textos de alunos se pauta principalmente pelo caminho da tradição, que considera a língua um conjunto de regras a serem seguidas. Com isso, corrigir/avaliar textos é muito mais apontar erros do código, ou corrigi-los, do que considerá-los como uma forma complexa e precisando atender a vários pontos, desde as unidades menores (ortografia, acentuação) até, e principalmente, as unidades maiores, que envolvem o objetivo comunicativo, o g $1 \mathrm{ero}$, a variedade lingüística, o destinatário, o veículo de divulgação, como apontam Ev: ngelist: et al. (op. cit.) e Ruiz (op. cit.). Desta forma, a relação entre concepções teór ad de 'íno.a e variação e a correção feita pelos professores não se apresenta de form tão $s$ mples: teoricamente, demonstram ter uma concepção interacionista de língua onfor e escreve Marcuschi, op. cit.), mas nas correções lançam mão de concepções e p. oc u unentos mais aproximados das correntes prescritivas, baseadas na gramática rmativ (tradicional).

\section{REFERÊNCIAS BIBLIOGRÁFICAS}

BAGNO, M. (2002). et al. Língua materna. São Paulo: Parábc

BAKHTIN, M. (1995). Marxismo e filosofia da linguag m. 7.ed. Sà Paulo: Hucitec.

EVANGELISTA, A. A. M. e outros. (1998). Prof sor-l-itor - aıuno-autor: reflexões sobre avaliação do texto escolar. Cadernos CEALE, v. III, ano II, oul.

HABERMAS, J. (1983). Conhecimento e ntere an: Loleção Os Pensadores. São Paulo: Abril Cultural.

LÜDKE, M. \& MEDIANO, L. (1992). (coords., Concepção de avaliação. In: $1^{\circ}$ grau: uma análise soci rógica Campinas: Papirus, p.107-114. . Avaliação na escola de

MARCUSCHI, L.A. (Acesmem. ?0 jul.? 03). O papel da lingüística no ensino de língua. Conferência proferida no $1^{\circ}$ Encontro de Es. dos Lingüístico-Culturais da UFPE, dez.2000. Disponível em: http:// www.marcosbag o.com.bi wonteudo/forum/marcuschi.htm.

MARCUSCHI e. (200. Os destinos da avaliação no manual do professor.In DIONISIO, A.P. \& BEZERRA, M.A. org Y livro didático de português: múltiplos olhares. Rio de Janeiro: Lucerna, p.139-150.

MAT JS, A M de A. (2002). O professor no espelho: conscientização e mudança pela auto-observação. Revista leira de lingüística aplicada, Belo Horizonte, v.2, n.1, p.121-155.

P RK TOUD, P. (1999). A avaliação entre duas lógicas. In: aprendizagens. Porto Alegre: Artes Médicas Sul, p.09-23. . Avaliação: da excelência à regulação das

REINALDO, Ma. A.G. de M. (2001). Teoria e prática na formação do professor. Boletim da ABRALIN, Fortaleza, v.26, n. especial, I, p. 163-165.

RUIZ, Eliana. (2001). Como se corrige redação na escola. Campinas: Mercado das Letras, p.13-73.

SERAFINI, M. T. (1989). Como escrever textos. Rio de Janeiro: Globo, p.107-145. 
TARDIF, M. (2002). Saberes docentes e formação profissional. 2.ed. Petrópolis: Vozes.

VYGOTSKY, L. (1987). Pensamento e linguagem. São Paulo: Martins Fontes.

WALLACE, M. J. (1991). Training foreign language teachers: a reflective approach. Glasgow: Cambridge University Press.

\section{RESUMO}

Este artigo tem dois objetivos principais. O primeiro consiste em identificar conceitos de lí gua e variedade lingüística subjacentes à correção de textos escolares por professores de língua materna enquant o segundo diz respeito à relação entre esses conceitos e a correção/avaliação. Para isso hs daçõ o foram corrigidas e avaliadas por um grupo de futuros professores. Como ocorre normalm nte, for olicitada uma justificativa. A análise se baseou em princípios teóricos relacionados com a formaç o do $\mathrm{r}$ ofessor, correção/avaliação bem como conceitos de linguagem. Os resultados apontam qu nofessu corrigem, principalmente, seguindo regras formais, apesar de, durante a justificativa, eles se 1 fer an à informação textual-discursiva, mostrando que eles adquiriram um discurso teórico mo erno ac mpanhado por uma prática tradicional.

Palavras-chave: avaliação, produção escrita, língua materna, formacão do pru essor. 